\title{
Reduction of the 59 -day error signal in the Mean Sea Level derived from TOPEX/Poseidon, Jason-1 and Jason-2 data with the latest FES and GOT ocean tide models
}

Lionel Zawadzki ${ }^{1}$, Michaël Ablain ${ }^{1}$, Loren Carrere ${ }^{1}$, Richard D. Ray ${ }^{2}$, Nikita P. Zelensky ${ }^{3}$, Florent 5 Lyard $^{4}$, Amandine Guillot ${ }^{5}$, Nicolas Picot ${ }^{5}$

${ }^{1}$ Collecte Localisation Satellite (CLS), Ramonville Saint-Agne, France

${ }^{2}$ Goddard Space Flight Center (NASA/GSFC), Greenbelt, MD USA

${ }^{3}$ SGT Inc., Greenbelt, MD USA

${ }^{4}$ Laboratoire d'Etudes en Géophysique et Océanographie Spatiales (LEGOS), Toulouse, France

$10 \quad{ }^{5}$ Centre National d'Etudes Spatiales (CNES), Toulouse, France

Correspondence to: Lionel Zawadzki (Lionel.Zawadzki@cls.fr)

Abstract. Mean sea level (MSL) is a prominent indicator of climatic change (Ablain et al. 2015; Cazenave et al.

15 2014; Leuliette and Willis 2011), and is therefore of great scientific and societal interest. Since the beginning of the altimeter mission TOPEX/Poseidon, followed by Jason-1 and Jason-2 on similar orbits, and many other missions on different orbits (ERS, EnviSat, ...etc.), MSL products became essential to the comprehension of Global ocean circulation.

Since early in the TOPEX/Poseidon mission (Nerem 1995) a suspicious signal, having period near 59 days and amplitude of roughly $5 \mathrm{~mm}$, was apparent in the GMSL record. Compared with the 4-5 $\mathrm{mm}$ amplitude of the annual signal (Minster et al.

20 1999), the suspicious 59-day signal has understandably attracted attention. Moreover, the same signal has been subsequently detected in Jason-1 and later Jason-2 MSLs. In 2010, it was the subject of a dedicated session at the Ocean Surface Topography Science Team (OSTST) meeting in Lisbon. The conclusions were this signal is the aliasing of a higher frequency error inherited from the tide model correction: the semi-diurnal wave S2. The source of this error was mainly attributed to TOPEX measurements which are assimilated in ocean tide models. When these models are used in the computation of TOPEX/Poseidon MSL, most of the error cancels. However, this error is communicated to Jason-1 and Jason-2 MSLs.

Since 2010, considerable efforts have been undertaken within the ocean tide community in order to correct ocean tide S2waves from this error, particularly in the Goddard Ocean Tide (GOT) and Finite Element Solution (FES) latest versions. The present paper assesses, quantifies and characterizes the reduction of the 58.77-day error thanks to the latest releases.

\section{Introduction}


Ocean Sci. Discuss., doi:10.5194/os-2016-19, 2016

Manuscript under review for journal Ocean Sci.

Mean sea level (MSL) is a prominent indicator of climatic change (Ablain et al. 2015; Cazenave et al. 2014; Leuliette and Willis 2011), and is therefore of great scientific and societal interest. The accurate monitoring of global sea level has been made possible mainly by developments in satellite altimetry. These advances represent a combination of the most precise and accurate measuring instruments, updated geophysical corrections (Legeais et al 2014), and the determination of accurate

5 satellite orbits up to the $1-\mathrm{cm}$ level thanks to the maintenance of the technology and geodetic infrastructure (Rudenko et al 2012).

However, the characterization and reduction of errors in the sea-level records remain major tasks, both for ongoing (Jason-2, Cryosat-2,etc.) (Couhert et al. 2015) and retired missions (TOPEX/Poseidon, Jason-1, Envisat,etc.) (Ollivier et al. 2012). This paper addresses one such error which is apparent in the TOPEX-Jason series of satellites, and especially in the Global

10 Mean Sea Level (GMSL) time series produced from these satellites.

Since early in the TOPEX/Poseidon mission (Nerem 1995) a suspicious signal, having period near 59 days (more precisely, at 58.77 days but noted 59 days in this paper) and amplitude of roughly half a cm, was apparent in the GMSL record. Compared with the 4-5 mm amplitude of the annual signal (Minster et al. 1999), the suspicious 59-day signal is relatively large and has understandably attracted attention. In 2010, it was the subject of a dedicated session at the Ocean Surface

15 Topography Science Team (OSTST) meeting in Lisbon (Callahan 2010; Desjonqueres 2010; Ablain et al 2010; Zelensky et al 2010; Leuliette et al 2010; Cerri 2010). Some conclusions of this meeting were: first, the signal has no geophysical reality and is an error. Second, the 59-day signal can be due to aliasing of a 12-hour error with the TOPEX/Jason repeated orbit (repeat period 9.91564 days), although the effects of a periodic 59-day heating/cooling cycle on the TOPEX altimeter, as well as other satellite effects, could not be ruled out. Third, changing the ocean tide correction in the Jason-1 GMSL record

20 from GOT4.7 to FES2004 decreases the signal amplitude from $4.0 \mathrm{~mm}$ to $0.5 \mathrm{~mm}$. On the other hand, the same change in TOPEX GMSL record results in an increase of the signal amplitude from 0.7 to $1.3 \mathrm{~mm}$. To some extent, these results depend on which version of Geophysical Data Record (GDR) is examined.

It is thus evident that the 59-day signal is closely related to the tide models used for processing the altimeter data as well as to the methods by which those models were originally created. This paper thus proposes an extensive discussion on tide models, beginning with Section 0. It is important to understand, however, that the source(s) of the anomalous signals in MSL cannot be wholly attributed to errors in tide models. Other errors are involved, and these are discussed briefly in Section 0. In addition, two important conclusions are: (i) the appearance of 59-day signals can stem from altimeter data processing methods that are inconsistent with the methods used during tide-model development. Inconsistent, inaccurate, or incomplete data processing can lead to 59-day signals even if the tide models are perfect. (ii) The TOPEX and Jason satellites are 30 fundamentally inconsistent at the period of 59 days, and therefore no model can completely remove the 59-day signals in both MSL series simultaneously. The source of this inconsistency is still not completely understood.

The present paper aims at assessing, quantifying and characterizing the reduction of the 59-day error using several new ocean tide solutions, namely GOT4.10 and FES2014. It is the continuation of (Ablain et al. 2010) completed with (i) an 
Ocean Sci. Discuss., doi:10.5194/os-2016-19, 2016

Manuscript under review for journal Ocean Sci.

exhaustive as possible list of potential causes for 59-day errors; (ii) analyses of the 59-day error in the latest GOT and FES releases; (iii) regional analyses in addition to the global ones; (iv) analyses on Jason-2 MSL record in addition to TOPEX and Jason-1; and (v) the use of an updated and more accurate pure hydrodynamic solution to better characterize the error reduction.

\section{Possible causes of 59-day variability}

In response to gravitational tugs from the Earth's equatorial bulge, the TOPEX and Jason satellite orbit planes precess in inertial space at a rate of $-2.08 \mathrm{deg} / \mathrm{day}$, where the negative sign denotes retrograde precession, or westward, opposite to the direction of Earth's rotation rate. Relative to the sun, the rate is $-3.065 \mathrm{deg} / \mathrm{day}$, with corresponding period of 117.4 days.

10 The angle between the orbit plane and the Earth-Sun direction, generally denoted $\beta$ ', sweeps through one full cycle in this period. The satellite orbit plane is thus aligned edge-on with the Earth-Sun direction twice every precession period, i.e. every 58.7 days. This alignment with the Earth-Sun direction is the ultimate cause of the 59-day variability seen in MSL, but the proximate cause is myriad and complex.

The 59-day satellite precession also describes how local time is sampled by the satellites, and since local time defines the

15 phase of the principal solar semidiurnal tide S2, that tide is sampled over its full cycle once every 59 days. That is, the 2 cycle-per-day solar tide is aliased to 59 days by the satellite orbit. This fact often leads to the claim that 59-day errors in MSL are caused by errors in the S2 tide models, but that notion is too simplistic. There are many errors induced by solar forcing and these all tend to occur at the 59-day alias. We here mention a few possible non-ocean-tide errors; some are unique to the TOPEX and/or Jason altimeter or to modeling errors in the TOPEX or Jason data processing.

20 a. Non-conservative forces acting on the satellite (orbit error). Radiation-pressure forcing on the satellites is clearly a function of $\beta$, both the magnitude of the forcing and its direction (cross-track versus radial). The modeling of this force is satellite-specific since it must account for the complex shape and surfaces of each spacecraft (Ziebart et al. 2005). Modeling errors will thus have some dependency on $\beta$ '. So too will errors in modeling of atmospheric drag, since the atmosphere's density at high altitude depends on $\beta^{\prime}$. Modeling of both these effects are reviewed by (Lemoine et al. 2010) and (Cerri et al.

25 2010).

b. Motion of TOPEX center of mass (CM) (altimeter correction, orbit error). The TOPEX CM uncertainty is largely due to unmodeled thermal warping of the solar array which will directly affect the altimeter measurement and to a lesser extent POD. The altimeter correction shows a sinusoïdal variation over each orbit revolution, whose amplitude varies with $\beta^{\prime}$. There is such a correction on the TOPEX GDR whose amplitude reaches about $8 \mathrm{~mm}$ for zero $\beta^{\prime}$. Independent analysis

30 suggests the effect may be twice as large (Kubitschek \& Born 2000). The CM variations due to solar array thermal warping are not included in TOPEX POD.

c. Ionospheric delay (altimeter correction). The free-electron content of the ionosphere is strongly dependent on local solar time. Thus, any error in the altimeter ionosphere correction will tend to have a $\beta$ ' dependence. TOPEX and Jason have 
Ocean Sci. Discuss., doi:10.5194/os-2016-19, 2016

Manuscript under review for journal Ocean Sci.

dual-frequency altimeters to minimize this error. The raw correction requires smoothing (Imel 1994) and is somewhat correlated with the sea-state bias correction (Zlotnicki 1994), presumably because both are functions of the radar frequency. d. Satellite tracking errors (orbit error). Ionospheric errors in GPS and DORIS tracking (e.g., from second-order effects) will have a dependence on local time, and thus lead to potential 59-day errors. The problem is compounded in Jason-

51 data, because its DORIS ultra-stable oscillator was unduly sensitive to radiation when overflying regions of weak geomagnetic field (Lemoine \& Capdeville 2006)

e. Motion of tracking stations (orbit error). Thermally induced motions of the ground-based tracking stations can probably be discounted (Saunier et al. 2016; Munekane 2013), but ocean and atmospheric loading displacements at ground stations could conceivably contribute.

10 f. Atmospheric tides in ocean loading (altimeter correction). The S2 atmospheric tide, of amplitude roughly $1 \mathrm{mb}$, can affect a number of altimeter corrections. For example, any leakage of S2 tidal signals into an atmospheric loading correction (either dynamic or isostatic) will lead to errors, since the ocean's response to S2 pressure loading is already modeled by the tide models. Moreover, adopting an inverted barometer assumption for this response would represent a serious error.

g. Atmospheric tides in range corrections. Somewhat related to (f) is a subtle effect of atmospheric tides in the dry

15 tropospheric range correction (altimeter correction). Here the full air-tide signal should be modeled, since it accounts for a true signal delay. However, in several generations of GDRs, the delay was computed from 6-h surface pressure data derived from a global operational weather model. Sampling at $6 \mathrm{~h}$ is inadequate to capture S2, so the dry-tropospheric effect was inaccurate, and this error went directly into the resulting altimeter data as an S2 tidal error. This error is present in all TOPEX GDRs as all this writing (i.e. through MGDR-B); it was present in Jason-1 GDR-A, but was significantly reduced in

20 GDR-B and later versions. The fix essentially follows a suggestion of (Ponte \& Ray 2002), which depends on a climatological model of S2. An atmospheric pressure model with 3-hour (or faster) sampling and more accurate barometric tides (Schindelegger \& Ray 2014) would be preferable.

h. Atmospheric tides in crustal loading (altimeter correction). To our knowledge, altimeter data are never corrected for crustal loading by the $\mathrm{S} 2$ atmospheric tides. There is some suggestion that the effect, although very small, is detectable (Ray

25 2013). Errors in crustal loading lead to 59-day errors in MSL unless they instead are absorbed into the altimeter-constrained ocean tide models.

i. Periodic changes in heating/cooling of the satellite payload (altimeter instrument). The orientation of the spacecraft with respect to the sun changes with a 59-day periodicity causing a periodic variation in thermal conditions of the altimeter and other instruments. The sensitivity of the altimeter and other instruments to such thermal changes may result in a periodic

30 variation of the altimeter range measurement itself. Although analysis has shown 59-day temperature changes of the Jason$1 / 2$ instruments should have a negligible effect on the altimeter range measurements (Desjonqueres 2010), corresponding analysis for TOPEX/Poseidon has not been conducted. Also difference between TOPEX A and B 59-day amplitudes suggests instrumental causes (Zelensky et al. 2010). 
Ocean Sci. Discuss., doi:10.5194/os-2016-19, 2016

Manuscript under review for journal Ocean Sci.

In light of this long list of possible error sources that conceivably cause 59-day errors in sea level, it is clear that even perfect ocean-tide models are no panacea for eliminating the 59-day problem. It is also clear that consistency in the algorithms and corrections being applied to altimetry must be carefully enforced. For example, an empirical tidal model that might be expected to absorb some of these (non-tidal) errors will still lead to 59-day errors in MSL without such enforced consistency.

5 The altimeter community has seen repeated cases of this inconsistency from source ( $\mathrm{g}$ ) above, since some users have updated their TOPEX dry-tropospheric corrections and some have not, and if users' adopted tide model did or did not use the identical correction then 59-day residual errors will be either reduced or inflated. The same caution is required when testing models-see below.

Notwithstanding the many possible error sources listed above, the dominant source of 59-day errors in altimetric sea levels is

10 still probably errors in the S2 ocean tide models, a subject to which we now turn (Callahan 2010; Desjonqueres 2010; Ablain et al 2010; Zelensky et al 2010; Leuliette et al 2010; Cerri 2010).

\section{Description of FES and GOT Ocean tide models}

Since 2010, considerable efforts have been undertaken within the ocean tide community in order to understand how the 59-

15 day error in TOPEX-Jason MSL is related to the S2 ocean tide models. In particular, special tidal solutions were developed to explore various aspects of the problem, such as models relying on mostly TOPEX data versus mostly Jason data. Here we focus on two series of tide models: the Goddard Ocean Tide (GOT, computed by NASA Goddard) and Finite Element Solution (FES, computed by LEGOS/NOVELTIS/CLS/CNES). Several versions of each series have been used on most of the distributed GDRs.

20 GOT and FES ocean tide models are based on different approaches: GOT is an empirical model based on direct tidal analyses of altimetry measurements, whereas FES is a hydrodynamic model with assimilation of altimetry and in situ data. This suggests that GOT is theoretically more impacted by altimetry errors than FES, depending on the relative weighting between merging altimetry versus fitting hydrodynamics as employed in the FES solutions.

In this section, the FES and GOT ocean tide models are succinctly described, focusing on the S2 wave as it is likely to be the dominant source of 59-day error as described in previous section.

\subsection{Finite Element Solution (FES)}

FES is an ocean tide model based on a hydrodynamic solution and an assimilation process. From the oldest FES release to the latest, evolutions mainly involve improvements in the modeling (spatial resolution, bathymetry, dissipation, etc.), in the data assimilation techniques, and in the assimilated dataset (longer altimeter records, improved altimeter standards, improved

30 tidal gauges data processing, etc.). Altimeter records consist in Sea Level Anomaly (SLA) time series projected on the theoretical tracks using a Mean Sea Surface (MSS) field. As a consequence, errors in SLA records may be assimilated in FES solutions. However, FES hydrodynamic solution is already accurate and the assimilation process has thus a relatively 
Ocean Sci. Discuss., doi:10.5194/os-2016-19, 2016

Manuscript under review for journal Ocean Sci.

Published: 25 May 2016

(c) Author(s) 2016. CC-BY 3.0 License.

small impact (Lyard et al. 2006) when compared to a stochastic model. In this paper, four FES releases are compared: FES2004 (Lyard et al. 2006), FES2012 (Carrere et al. 2012), FES2014 (Carrere et al. 2015; Lyard et al. in preparation), and the pure hydrodynamic solution of FES2014 that will be referred to as "FES2014 HYDRO" in this paper.

The S2-wave of FES2004 assimilated only TOPEX and tidal gauges records (Lyard et al., 2006). However, it contains a

5 problem with the Dry Tropospheric Correction (DTC) used in TOPEX GDRs(see above discussion), though it is apparently offset by the hydrodynamic approach. As mentioned previously, this systematic error has no significant impact on TOPEX SLA record if the same DTC, containing the same problem, is used in the computation of SLA and the tide model. In the next release, FES2012, the TOPEX SLA record was corrected from this problem, extended with the end of the mission and benefited from updated standards. Jason-1 and Jason-2 SLA records were also assimilated, but no tidal gauges records were

10 used (Carrere et al. 2012). Finally, in the latest release, FES2014, TOPEX SLA record benefited from updated standards, as well as Jason-1 and Jason-2 SSH extended records, and tidal gauge measurements were again assimilated (Carrere et al. 2015; Lyard et al. in preparation).

\subsection{Global Ocean Tide (GOT)}

GOT releases are based on empirical tidal analyses of multi-satellite altimeter data which consist in altimetric residuals

15 relative to an adopted prior model (combination of several tide models), see (Ray 1999; Ray 2013). Therefore, it is significantly impacted by the potential errors in altimetric SLA records. By comparison to the hydrodynamic approach, it is not impacted by hydrodynamic approximations, but it may include other modeling errors inherent in the stochastic approach. In this paper, three GOT releases are compared: GOT4.7, GOT4.8, and GOT4.10 (Ray 2013).

The S2-wave in GOT4.7 is based on TOPEX GDRs only, and as FES2004, it contains a problem with the Dry Tropospheric

20 Correction (DTC) used in TOPEX GDRs. This problem has been correctedin GOT4.8 and GOT4.10 (Ray 2013). Moreover, in GOT4.10, only Jason-1 and Jason-2 SLA records were used for the S2-wave computation according to the conclusions of OSTST 2010.

\subsection{In situ assessment of FES and GOT models}

Because the FES and GOT models (aside from FES2014-HYDRO) are all heavily constrained by satellite altimetry, and the

25 tests in Sections 4 and 5 are based on altimetry, it is useful to have some independent (i.e., non-altimeter) assessment of the tide models. In a recent comprehensive review of global models, (Stammer et al. 2014) employed a variety of tests. One of the most powerful was comparison of models against harmonic constants derived from a set of high-quality bottom-pressure measurements. In this section we compare S2 bottom-pressure harmonics with our seven versions of FES and GOT models. The results help clarify the main conclusions discussed below in Sections 0 and 0.

30 We use the same set of 151 bottom-pressure stations employed by (Stammer et al. 2014) and described in much greater detail by (Ray 2013). Most of the pressure time series were multi-year hourly (or sub-hourly) measurements; the median length of time series was 567 days. The S2 harmonic constants were adjusted to remove the effect of the S2 atmospheric 
Ocean Sci. Discuss., doi:10.5194/os-2016-19, 2016

Manuscript under review for journal Ocean Sci.

pressure tide. Amplitudes were converted to equivalent sea-surface heights by use of a three-dimensional climatological seawater density.

RMS differences between the 151 bottom-pressure data and the S2 FES and GOT models are listed in Table 1. The table also includes a separate column based on only 39 stations located in tropical latitudes. The latter stations are often more sensitive

5 to some of the S2 altimeter errors discussed in this paper (e.g. dry-tropospheric errors arising from problems with S2 air tides), and indeed some of the differences among models do appear more pronounced for the tropical stations.

The largest RMS is obtained for the unconstrained FES2014-HYDRO model, which is not surprising (in fact, the surprise is how accurate such an unconstrained model turns out to be). The RMS values show good reduction from FES2004 through FES2012 and FES2014, confirming general progress in modeling. Note, however, that interpretation of the FES2014 values

10 is complicated by the fact that that tide solution assimilated our test stations, so the RMS is to some extent merely a function of the weighting used in the assimilation. All other models in Table 1 are independent of the test stations.

The RMS results are consistent with many of the conclusions discussed below. For example, after the unconstrained model, the worst RMS values are obtained for FES2004 and GOT4.7, and both of these models used TOPEX data (no Jason data) with the dry-tropospheric error. GOT4.8 had a repaired troposphere correction, and its RMS is considerably reduced. The

15 RMS for GOT4.10 is better than for GOT4.8, which is consistent with our conclusion below that the 59-day problem is more significant for TOPEX than for Jason. FES2012, which is based on both TOPEX and Jason, has an RMS falling between GOT4.8 and GOT4.10 (at least for the tropical stations), suggesting that it does in some sense represent an average of TOPEX and Jason.

\begin{tabular}{lccccc}
\hline Model & Used TOPEX & Used Jason & $\begin{array}{c}\text { Corrected Dry } \\
\text { Troposphere }\end{array}$ & $\begin{array}{c}\text { RMS (mm) } \\
\mathbf{1 5 1} \text { global }\end{array}$ & $\begin{array}{c}\text { RMS (mm) } \\
\text { 39 tropical }\end{array}$ \\
\hline FES2004 & Yes & No & No & 6.02 & 8.02 \\
FES2012 & Yes & Yes & Yes & 4.07 & 3.50 \\
FES2014 Hydro & No & No & - & 6.98 & 8.67 \\
FES2014* & Yes & Yes & Yes & 2.67 & 5.39 \\
\hline GOT4.7 & Yes & No & No & 5.07 & 3.71 \\
GOT4.8 & Yes & No & Yes & 3.69 & 3.06 \\
GOT4.10 & No & Yes & Yes & 3.30 & \\
\hline
\end{tabular}

* FES2014 assimilated the test stations

Table 1 : RMS differences with S2 bottom-pressure measurements

\section{Reduction of the 59-day MSL error with the latest GOT and FES releases}


Ocean Sci. Discuss., doi:10.5194/os-2016-19, 2016

Manuscript under review for journal Ocean Sci.

\subsection{Methods}

The analyses performed in this paper rely on the estimation of 59-day signals amplitude and the corresponding formal errors computed with the Ordinary Least Square (OLS) approach. The methodologies are very similar at global and regional scales. At global scale, a GMSL record is first computed for TOPEX, Jason-1 and Jason-2 with the AVISO methodology

5 (aviso.altimetry.fr/msl ; Henry et al. 2014) with a one-cycle sampling: the 254 tracks corresponding to 1 cycle are first averaged in a $3^{\circ} \times 1^{\circ}$ grid, then the grid itself is averaged. Besides, a selection is performed to allow a comparison on geographical areas where the tide models have the highest quality: low oceanic variability $\left(<20 \mathrm{~cm}^{2}\right)$ and deep depths $(<1000 \mathrm{~m})$. The TOPEX record is computed over cycles 10-383 (10.1 years), the Jason-1 record over cycles 1-374 (10.1 years), and the Jason-2 record over cycles 1-252 (6.8 years). The analysis periods of TOPEX and Jason-1 records have been

10 chosen equal to ensure the same accuracy of the results for both missions. Even though Jason-2 record is shorter, the analyses performed still have a nearly comparable level of accuracy. The standards used are described on the AVISO website (aviso.altimetry.fr/msl) except, for the ocean tide correction: TOPEX/Poseidon measurements are based on MGDR products, Jason-1 on GDR-C products and Jason-2 on GDR-D products. A revised dry troposphere correction is used for the three missions taking into account the atmospheric S2 tide correction (Ponte \& Ray 2002). Thus, TOPEX, Jason-1 and

15 Jason-2 measurements used in this paper are theoretically more consistent with ocean tide solution GOT4.8 and FES2012 or later releases than with GOT4.7 and FES2004.

These MSL records contain a trend and high-amplitude seasonal signals (annual and semi-annual) that are removed to allow an accurate estimation of the 59-day amplitude and particularly the associated formal error. For the same reason, a band-pass filter centered on 59 days with a width corresponding to Rayleigh criterion is applied in order to keep only the signal of interest. Then, a sine and a cosine with 59-day periods are fitted to the time series with the OLS approach. The 59-day signal amplitude is deduced from the quadratic sum of the fitted sine and cosine amplitudes. The corresponding formal error is deduced from the quadratic sum of the fitted sine and cosine formal errors as well.

Without the band-pass filter, the 59-day amplitude estimate would not be significantly impacted. However, it would increase the variance of the difference between the fitted sine and the original time series, thus artificially increasing the formal error.

25 With this methodology, the formal error at global scale is estimated to $0.15 \mathrm{~mm}$ at confidence level $95 \%$ for the 3 missions and for all the ocean tide corrections considered.

At local scale, MSL grids are computed for every cycle in a $2^{\circ} \times 2^{\circ}$ mesh. Then the 59-day amplitudes and formal errors are estimated with the same methodology as for the global scale in each box by stacking the MSL grids. The uncertainties associated with these amplitudes have been estimated at $95 \%$ confidence level and are relatively high: about $6 \mathrm{~mm}$ in the

30 Indian and Pacific Oceans, $3 \mathrm{~mm}$ in the Atlantic Ocean, and up to $10 \mathrm{~mm}$ in the great ocean currents (ACC, Falklands, Kuroshio, Agulhas, and Gulf Stream).

It is important to understand that the spatial average of the resulting amplitude grid does not necessarily match the global amplitude estimate. Indeed, the global amplitude is directly computed with the global MSL record, averaging the local 
Ocean Sci. Discuss., doi:10.5194/os-2016-19, 2016

Manuscript under review for journal Ocean Sci.

Published: 25 May 2016

(c) Author(s) 2016. CC-BY 3.0 License.

phases in the process. In order to retrieve the global amplitude using the local amplitudes grid, one should take into account the local phases grid.

\subsection{Results at global scale}

In this section, the analyses are similar to (Ablain et al. 2010) but upgraded with the latest GOT and FES ocean tide models.

5 The amplitudes of the 59-day signal are estimated in TOPEX, Jason-1 and Jason-2 GMSL records with three versions of GOT and FES; results are shown in Figure 1.

In the case of GOT ocean tide model, using GOT4.8 allows diminishing the 59-day signal amplitude by 50\% compared with GOT4.7 for the three missions. This reduction was expected thanks to the correction of the atmospheric tides S1/S2 in the TOPEX SLA record assimilated in GOT4.8, see previous section. Besides, the 59-day signal amplitude increases from 0.4

$10 \mathrm{~mm}$ with GOT4.8 to $1.5 \mathrm{~mm}$ with GOT4.10 in TOPEX MSL record. Symmetrically, the amplitude decreases from $1.5 \mathrm{~mm}$ with GOT4.8 to $0.4 \mathrm{~mm}$ with GOT4.10 in Jason-1 MSL record. This behavior is explained by the difference between GOT4.10 and GOT4.8 models: the assimilation of Jason-1 and Jason-2 data only in GOT4.10, instead of TOPEX data for GOT4.8, in the S2-wave computation. The results thus highlight an inconsistency between TOPEX and Jason-1/2 regarding the 59-day error. This led (Ablain et al. 2010) to suggest GOT4.7 -and by extension GOT4.8- contain an error due to

15 TOPEX SLA in their S2 waves. In other words, TOPEX SLA, before correction of ocean tide, contains an error that has been assimilated in GOT4.7 and GOT4.8. Thus, when either one of these ocean tide corrections is applied to TOPEX SLA, the errors offset one another. However, GOT4.10 does not assimilate this TOPEX error because it is based on Jason-1 and Jason-2 measurements. Therefore, when TOPEX MSL is corrected with GOT4.10, the error in TOPEX record is not compensated and is revealed. On the contrary, when Jason-1 or Jason-2 MSL records are corrected with GOT4.7 or GOT4.8, instead of being compensated, the 59-day error assimilated in these ocean tide corrections is propagated in the MSL records. Finally, when Jason-1 or Jason-2 MSL records are corrected with GOT4.10, there is no propagation of TOPEX 59-day errors as these errors are inherently not included in GOT4.10.

In the case of FES ocean tide model, see Figure 1, the 59-day error error is relatively small and much more consistent across the three different FES versions: the error in TOPEX MSL record stays around 1 mm with FES2004 and FES2014.

25 Similarly, the error in Jason-1 MSL record stays around $0.8 \mathrm{~mm}$ with FES2004 and FES2014. With FES2012, amplitudes are slightly different which may be attributed to the lower quality of S2 wave due to bathymetry error and of altimeter estimations for this wave, but also the absence of tidal gauges series assimilation in this release by comparison to FES2004 and FES2014 (Carrere et al. 2015; Stammer et al. 2014). However, the 59-day error stability within FES releases is evidently strengthened by the hydrodynamic model in the background, free from altimetry errors. 

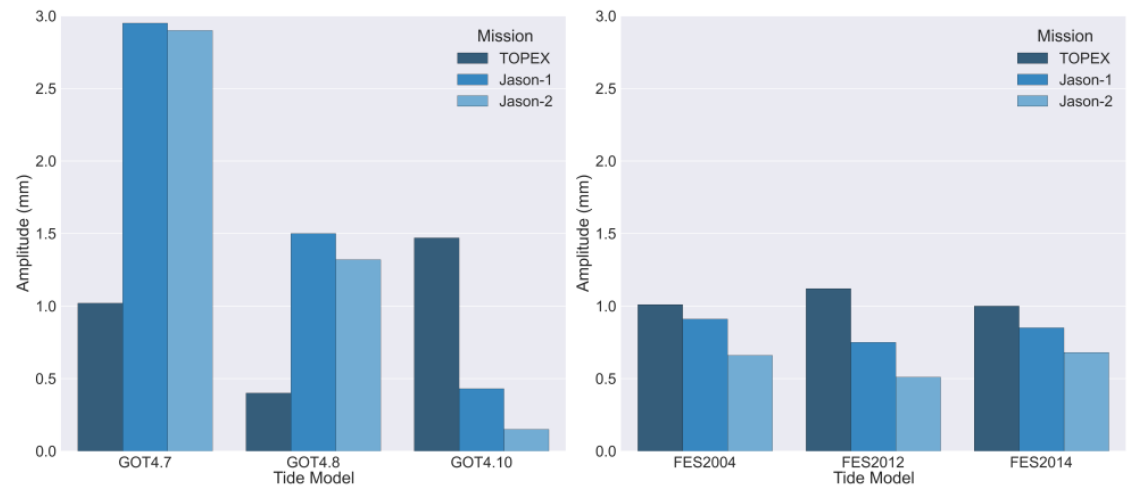

Figure 1: Amplitude of 59-day error in Global MSL of TOPEX, Jason-1 and Jason-2 with the latest GOT (left panel) and FES (right panel) releases. The reduction of the Jason-2 relative to Jason-1 may owe to the shorter Jason-2 time series

\subsection{Results at regional scale}

5 This section allows a finer description of the 59-day signal by comparison to (Ablain et al. 2010) with regional scale analyses in $2^{\circ} \times 2^{\circ}$ boxes for three GOT and FES releases. Results are plotted in Figure 2 for GOT and Figure 3 for FES releases. Besides, these results must be weighted against the large formal errors associated with these estimations, shown Figure 4. Jason-2 results are not shown, but are very similar to the results obtained for Jason-1.

Comparisons between GOT4.7, GOT4.8 and GOT4.10 for TOPEX and Jason-1 at regional scales are consistent with the global analyses. The upper panel of Figure 2 shows the MSL 59-day error is significantly larger for Jason-1 than for TOPEX MSL with GOT4.7 at low latitudes. In the Indian Ocean, amplitudes reach $15 \mathrm{~mm}$ in Jason-1 MSL whereas they remain below $6 \mathrm{~mm}$ for TOPEX. Similarly, in the Pacific and Atlantic Oceans, amplitudes in Jason-1 MSL are around $9 \mathrm{~mm}$ whereas it is negligible for TOPEX. When GOT4.8 is used (middle panel), the error decreases for both missions thanks to the implementation of the S1/S2 atmospheric tides correction in this release (Ray 2013). However, the 59-day amplitudes remain higher in Jason-1 MSL than in TOPEX, particularly in Indian and Atlantic oceans. Finally, when GOT4.10 is used, amplitudes increase in TOPEX MSL in the Indian Ocean (up to $8 \mathrm{~mm}$ ) and in a smaller area in the Atlantic Ocean (up to $7 \mathrm{~mm}$ ). However, amplitudes are similar in the Pacific Ocean. Symmetrically, the amplitudes in Jason-1 MSL decrease down to a negligible level in the same areas. This is explained, as in the previous section, by the fact that GOT4.10 assimilates only Jason-1 and Jason-2 data in the S2-wave. Therefore, if the 59-day errors visible in the Indian and the Atlantic oceans are due to the assimilation of TOPEX SSH in GOT4.7 and GOT4.8, it is expected that using GOT4.10 will decrease the error in Jason-1 and Jason-2 MSLs and increase it in TOPEX MSL. However, this hypothesis has only been proved at global scale by (Ablain et al. 2010). The next section will show th conclusion should be more nuanced at regional scales. 
Ocean Sci. Discuss., doi:10.5194/os-2016-19, 2016

Manuscript under review for journal Ocean Sci.

Published: 25 May 2016

(c) Author(s) 2016. CC-BY 3.0 License.

(c) (i)

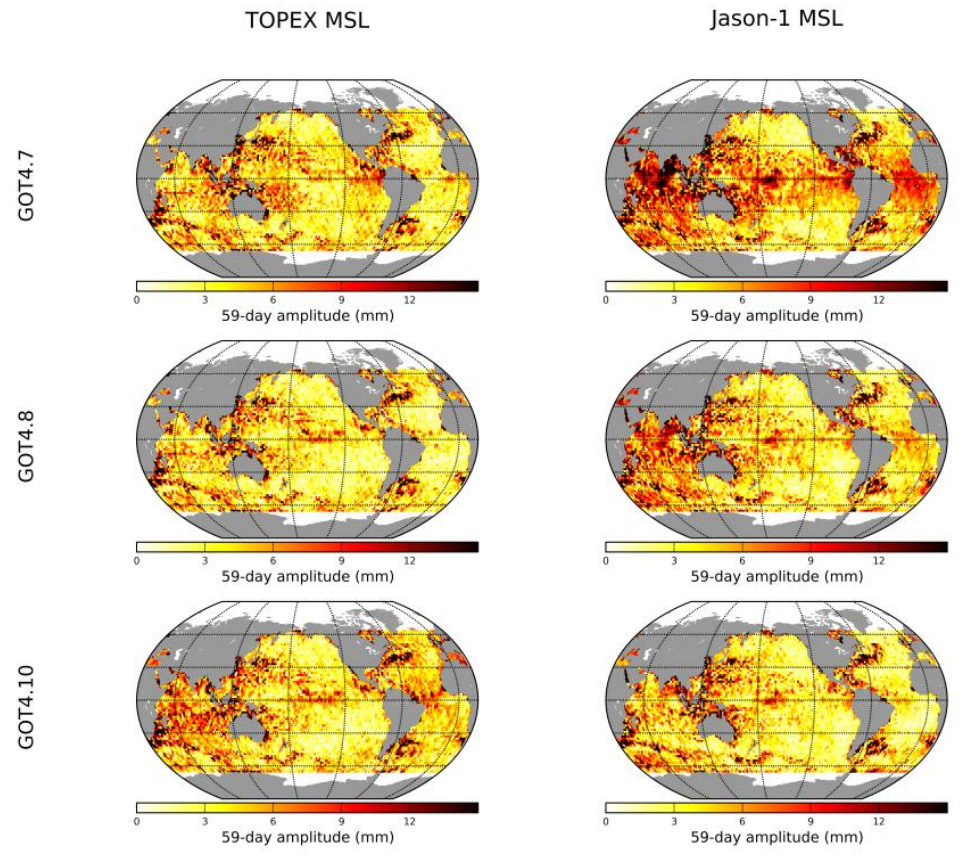

Figure 2: Amplitudes of 59-day error in TOPEX, Jason-1 and Jason-2 MSL in $2^{\circ} \times 2^{\circ}$ boxes with the latest GOT releases

The comparison between FES2004, FES2012 and FES2014 for TOPEX and Jason-1 at regional scales is also consistent with 5 the global analysis. The upper panel of Figure 3 shows the MSL 59-day error is significantly larger for Jason-1 than for TOPEX MSL with FES2004 in the Indian Ocean: amplitudes reach $12 \mathrm{~mm}$ in Jason-1 MSL whereas they remain below 6 $\mathrm{mm}$ for TOPEX. In the Atlantic Ocean, amplitudes in Jason-1 MSL are negligible whereas they are around $6 \mathrm{~mm}$ for TOPEX. When FES2012 is used (middle panel), the Pacific error decreases significantly for Jason-1 MSL, but a 6 mm error appears in the Atlantic over a small area in the Tropical band. The error in TOPEX MSL increases up to $7 \mathrm{~mm}$ over a large area in the Indian Ocean and reduces slightly in the Atlantic Ocean. Finally, using FES2014 model (lower panel), the error decreases for both Jason-1 and TOPEX MSLs in the Indian Ocean. This reflects the deep improvements of FES2014 by comparison to FES2012 in the Indian Ocean (Carrere et al. 2015). In the Atlantic and Pacific Oceans, however, only a small diminution of the amplitude is detectable. 
Ocean Sci. Discuss., doi:10.5194/os-2016-19, 2016

Manuscript under review for journal Ocean Sci.

Published: 25 May 2016

(c) Author(s) 2016. CC-BY 3.0 License.

(c) (i)
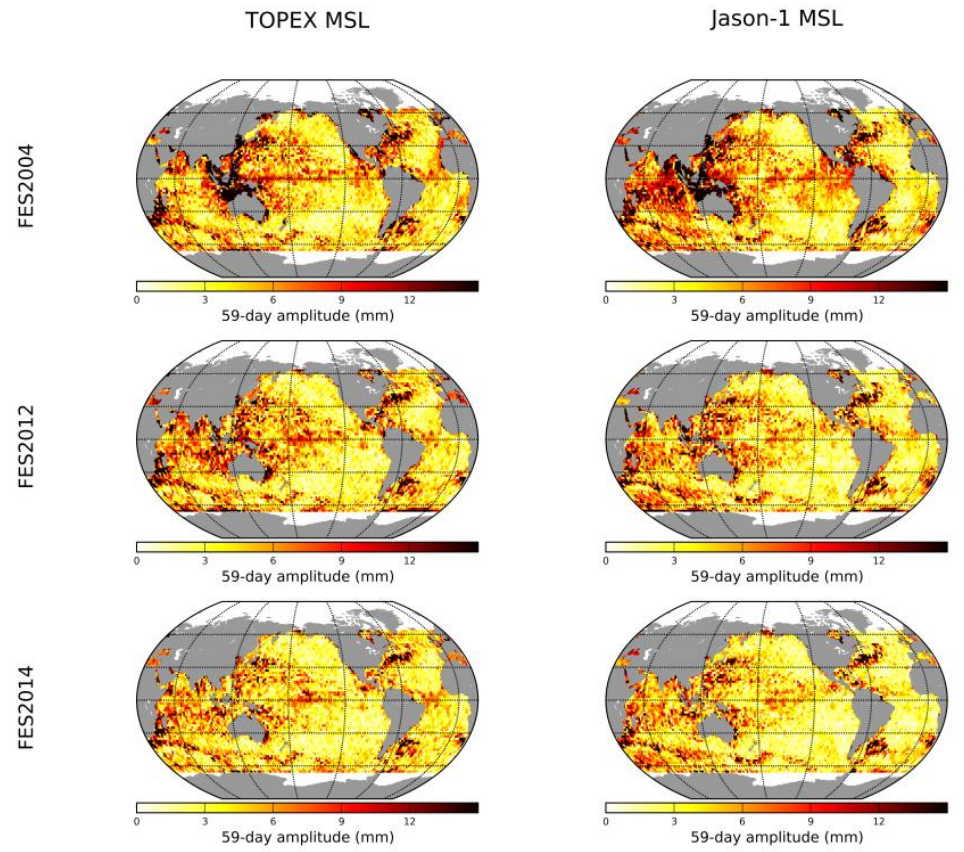

Figure 3: Amplitudes of 59-day error in TOPEX, Jason-1 and Jason-2 MSL in $2^{\circ} \times 2^{\circ}$ boxes with the latest FES releases

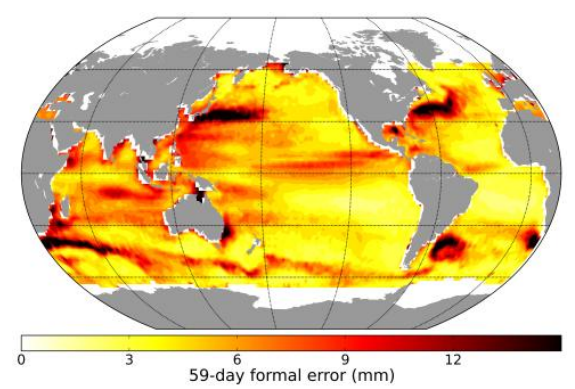

Figure 4: Formal errors on 59-day amplitude estimates in $2^{\circ} \times 2^{\circ}$ boxes

\section{Characterization of the 59-day error reduction}

This section aims at describing and quantifying the 59-day error that has been assimilated in GOT and FES ocean tide solutions using a hydrodynamic ocean tide model without any altimetry or in situ data assimilation. This analysis is performed at global and regional scales.

\subsection{Methods}

As mentioned earlier, the pure hydrodynamic solution FES2014 HYDRO

(Ablain et al. 2010) concluded the MSL 59-day error in TOPEX and Jason-1 records is mainly due to TOPEX SLA. In reaching this conclusion, TOPEX and Jason-1 global MSL records were corrected with a pure hydrodynamic ocean tide 
model and compared. Pure hydrodynamic solutions neither assimilate altimeter nor in situ records and contain intrinsic errors due to modelling uncertainties and approximations (barotropic model, bathymetry field errors, mesh resolution, dissipation parameterization, etc.). These errors are reduced thanks to the assimilation process to compute the FES solutions, though it may also lead to the assimilation of errors in the altimetry and in situ data. However, the interest of the

5 hydrodynamic solution in (Ablain et al. 2010) and the present study is that it is not polluted by any altimeter errors. In other words, even though the model contains intrinsic errors, these are independent from the altimeters and are thus identically propagated in TOPEX and Jason-1 MSL records. (Ablain et al. 2010) showed that, with this hydrodynamic correction, the 59-day signal in TOPEX MSL is higher than in Jason-1 MSL. This result highlights the existence of a 59-day error in TOPEX MSL and eventually that this error has necessarily been included in tide models assimilating these data, namely

10 GOT4.7 and GOT4.8, and to a lesser degree the FES models.

In this section, (Ablain et al. 2010) is first updated using the latest hydrodynamic solution of FES, noted "FES2014 HYDRO”, used to produce FES2014. It has a lower level of intrinsic error compared to the version used in this previous study (Carrere et al. 2015). Analyses have also been extended to Jason-2. Finally, it is then completed by comparing TOPEX and Jason-1 59-day MSL signals in $2^{\circ} \times 2^{\circ}$ boxes to better characterize the error at regional scale.

\section{$15 \quad 5.2$ Results at global scale}

The 59-day signal amplitudes estimated with the hydrodynamic solution (FES2014 HYDRO) at global scale are shown in Figure 5 compared to the amplitudes estimated with FES2014, for TOPEX, Jason-1 and Jason-2 global MSL records.

Comparing the amplitude obtained with FES2014 HYDRO for TOPEX (2.3 mm) with the amplitudes obtained for Jason-1 $(1.5 \mathrm{~mm})$ and Jason-2 $(1.6 \mathrm{~mm})$ suggests TOPEX MSL contains most of the 59-day error under investigation. If we consider

20 there is no 59-day error at all in Jason-1 and Jason-2 MSL records, results indicate the amplitude of the error in TOPEX global MSL is at least $0.7 \mathrm{~mm}$, the remaining $1.6 \mathrm{~mm}$ being due to the mean S2 tidal model error. This conclusion is consistent with (Ablain et al. 2010). However, we will see in the following section that this hypothesis is only partly true.

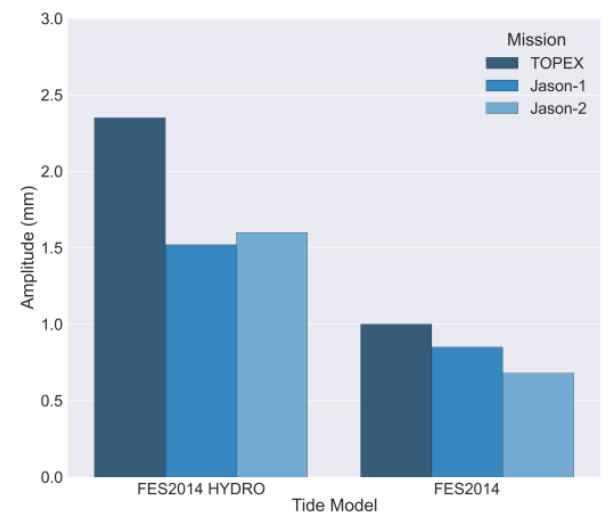

Figure 5: Amplitudes of 59-day error in TOPEX, Jason-1 and Jason-2 Global MSL with the latest FES2014 hydrodynamic

\subsection{Results at regional scale}


Ocean Sci. Discuss., doi:10.5194/os-2016-19, 2016

Manuscript under review for journal Ocean Sci.

Published: 25 May 2016

(c) Author(s) 2016. CC-BY 3.0 License.

The comparison between TOPEX, Jason-1 and Jason-2 MSL 59-day amplitudes in $2^{\circ} \mathrm{x} 2^{\circ}$ boxes when using FES2014 hydrodynamic solution (FES2014 HYDRO) allows a better characterization of the error at regional scale. This analysis has two purposes: (i) characterize the areas where altimetric error is assimilated in the models and (ii), differentiate potential TOPEX SLA errors from Jason-1 and Jason-2 ones locally. Figure 6 displays the differences between the amplitudes 5 estimated for these three missions. If all standards used In SLA computation were perfect and consistent in the three missions' records, the local amplitudes of each mission should not be significant. Therefore, the differences between the amplitudes of two sets of measurements show which one contains the largest error with respect to the other. The upper panel shows TOPEX-Jason-1 differences and indicates the 59-day error is mainly located in the Indian Ocean with 10 mm amplitude and is attributable to TOPEX. However, a 8-mm error is detected over a smaller area in the Atlantic Ocean at low

10 latitudes, attributed to Jason-1. A few small patterns are visible in equatorial Pacific, the eastern one is likely attributed to Jason and the other to TOPEX. The middle panel, comparing TOPEX and Jason-2 MSLs, shows similar results: it confirms the large TOPEX error in the Indian Ocean but also shows Jason-2 has the same 59-day error as Jason-1 in the Atlantic and Pacific. The lower panel indicates that 59-d errors are similar in Jason-1 and Jason-2 records. This error in Jason-1 and Jason-2 was not detectable at global scale since the TOPEX error in the Indian Ocean is significantly larger and thus

15 dominates the global MSL error. It is worth noting the correlation between the position of this signal in the Atlantic and the position of significant S2 signals in ionosphere correction (about $6 \mathrm{~mm}$ ). Analyses performed in the framework of the present paper (not shown) showed that about 3-mm out of the 8-mm amplitude detected in Jason-1/2 Atlantic MSL could be related to an error in Jason-1/2 ionosphere S2-waves. Besides, apart from ionospheric and ocean tide correction, all standards have been investigated but none of them could be linked to 59-day errors. Nevertheless, these issues require further examination. 
Ocean Sci. Discuss., doi:10.5194/os-2016-19, 2016

Manuscript under review for journal Ocean Sci.

Published: 25 May 2016

(c) Author(s) 2016. CC-BY 3.0 License.
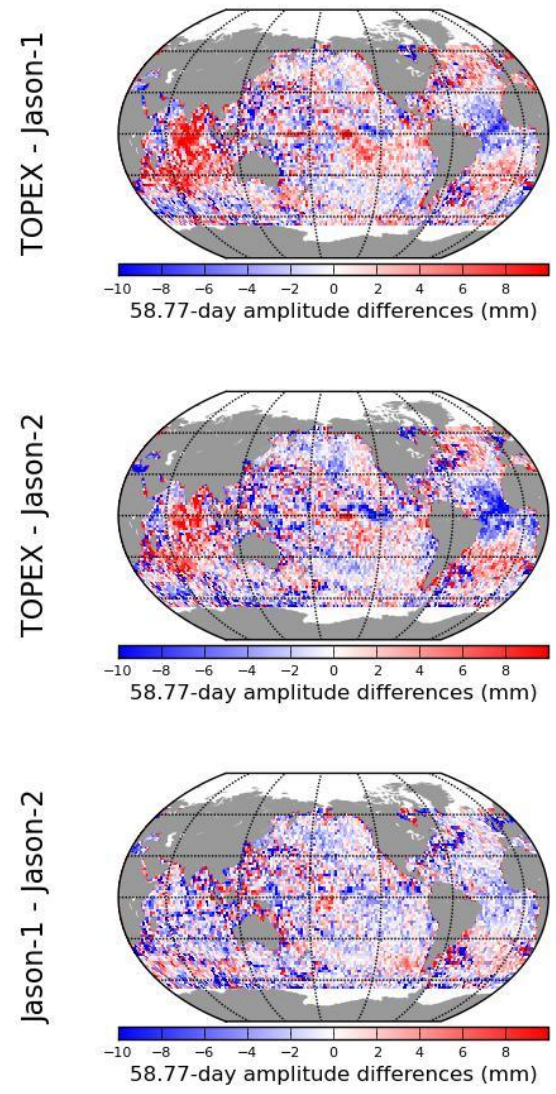

Figure 6: Difference of amplitudes of 59-day error between TOPEX, Jason-1 and Jason-2 MSL in $2^{\circ} \times 2^{\circ}$ boxes with FES2014 hydrodynamic solution

\section{Conclusion and outlook}

The purpose of this paper was to assess, quantify and characterize the reduction of the 59-day error in T/P, Jason-1 and Jason-2 MSL records with the latest GOT and FES ocean tide models.

The error reduction has been quantified through the analyses of MSL at global and regional scales when changing the ocean tide correction with the three latest official releases of respectively GOT (GOT4.7, GOT4.8, GOT4.10) and FES (FES2004,

10 FES2012, FES2014). Results show a significant decrease of the 59-day error down to a negligible level in Jason-1/2 MSL records with GOT4.10 by comparison to GOT4.8 and GOT4.7. However, using GOT4.10 significantly increases the error in TOPEX MSL record. This result is explained by the assimilation of Jason-1/2 data only in GOT4.10 model whereas GOT4.8 and GOT4.7 are based on TOPEX data. It has been suggested in this article that Jason-1/2 also contain a 59-day error, 
Ocean Sci. Discuss., doi:10.5194/os-2016-19, 2016

Manuscript under review for journal Ocean Sci.

though substantially smaller than TOPEX. Thus, using GOT4.10, the level of error could be artificially lower in Jason-1/2 MSL and higher in TOPEX.

The 59-day error in TOPEX, Jason-1 and Jason-2 MSL records exists but remains low and stable with the three FES releases (FES2004, FES2012, FES2014) at global scale. Indeed, FES relies primarily on a hydrodynamic model and data

5 assimilation, allowing the reduction of the weight of data errors in the solution, compared to a purely empirical model.

Regional analyses of the 59-day error amplitude have been performed. Results show errors in Atlantic, Pacific and Indian oceans at low latitudes in Jason-1 MSL using GOT4.7, GOT4.8 ocean tide corrections. These errors are almost completely transferred to TOPEX MSL using GOT4.10 which is consistent with results at global scale. Similar patterns are detected in Jason-1 MSL when using FES2004, particularly in Indian and Pacific Oceans. The pattern in the Indian Ocean is transferred

10 to TOPEX MSL when using FES2012, and becomes very weak with FES2014. The 59-day error remains very small in the Atlantic Ocean for the three FES releases.

The analysis of the 59-error reduction in Jason-2 MSL at both global and regional scale shows a strong consistency with Jason-1 MSL. The spatial patterns and amplitudes of the 59-day are similar between the two missions MSLs with all ocean tide models considered in the present paper. It should be kept in mind that the period of study is shorter for Jason-2 (7 years)

15 than for Jason-1 and TOPEX (10 years), leading to less accuracy in the amplitude estimates. However, the consistency between Jason-2 and Jason-1 confirms the results and the conclusions of the present paper.

The error source has been characterized by studying the impact of the S2 wave from FES2014 HYDRO. Without assimilation of altimetric data in the S2-wave, the hydrodynamic model is free from altimetry errors but not from modeling errors. By comparing the amplitudes of the 59-day signals in Jason-1 and TOPEX, most modeling errors cancel and reveal

20 the altimetry errors in each mission (Ablain et al. 2010). However, the possibility that the model errors, even though they are small, are in agreement with Jason or TOPEX 59-day errors has not been excluded. In this case, the following conclusions should be re-considered. Results at global scale are consistent with previous studies: the 59-day error is mainly induced by TOPEX measurements. At regional scale, the study shows large patterns attributed to TOPEX errors in the Indian Ocean, but also patterns attributed to Jason-1 and Jason-2 errors in the Atlantic Ocean at low latitudes. Small patterns due to both

25 TOPEX and Jason errors are visible in the equatorial Pacific.

The retroactivity between altimetry measurements, ocean tide models, orbits determination, and other standards fosters real difficulty for tracking down the origin of these SSH errors. The ultimate cause of 59-day errors is understood and clearly linked to the inaccurate account of the $\beta$ ' angle in one or several standards used in MSL computation. However, despite multiple side-analyses based on the considerations listed in Section 2 (results not shown), the proximate cause of this error remains today a puzzle. MSL records may of course easily be filtered to remove this error and allow studies at climate scale. However, the accurate characterization of this error is a necessary step to better understand altimetry errors and how standards impact each other. Besides, studies at climate scale require low levels of error but also consistency from one mission to the next: (Zawadzki \& Ablain 2016) showed the importance of this criterion for the accuracy of TOPEX/Jason-1 and Jason-1/Jason-2 relative biases estimation and its impact on the reference MSL record trend accuracy. 


\section{Acknowledgements}

This work is the result of a close and valuable collaboration between NASA/GSFC, SGT Inc., CNES LEGOS and CLS. On the CNES/CLS/LEGOS side, studies were performed in the framework of the FES2014 project supported by CNES. Authors would also like to thank M. Cancet (NOVELTIS) for her participation.

\section{Bibliography}

Ablain, M. et al., 2010. Analysis of the 58.74-day signal observed on the mean sea level derived from Jason-1\&2 and TOPEX/POSEIDON data. In OSTST 2010, Lisbon. Available at: http://www.aviso.altimetry.fr/en/user-corner/science-teams/sci-teams/ostst-2010/ostst-2010presentations.html.

Ablain, M. et al., 2015. Improved sea level record over the satellite altimetry era (1993-2010) from the Climate Change Initiative project. Ocean Science, 11(1), pp.67-82. Available at: http://www.ocean-sci.net/11/67/2015/os-11-67-2015.html [Accessed May 6, 2015].

15 Callahan, P., 2010. A brief review of TOPEX center of mass correction algorithm. In OSTST 2010, Lisbon. Available at: http://www.aviso.altimetry.fr/en/user-corner/science-teams/sci-teams/ostst2010/ostst-2010-presentations.html.

Carrere, L. et al., 2012. FES 2012: A NEW GLOBAL TIDAL MODEL TAKING ADVANTAGE OF NEARLY 20 YEARS OF ALTIMETRY. In OSTST 2012, Venice. Venice. Available at: http://www.aviso.altimetry.fr/fileadmin/documents/OSTST/2012/oral/01_thursday_27/03_tides/04 _TID_Carrere2.pdf.

Carrere, L. et al., 2015. FES 2014, A NEW TIDAL MODEL ON THE GLOBAL OCEAN WITH ENHANCED ACCURACY IN SHALLOW SEAS AND IN THE ARCTIC REGION. In OSTST 2015, Reston. Available at: http://meetings.aviso.altimetry.fr/programs/abstractsdetails.html?tx_ausyclsseminar_pi2\%5BobjAbstract\%5D=1568\&cHash=9e77dc6705a6353aba4d0 eb6482da08a.

Cazenave, A. et al., 2014. The rate of sea-level rise. Nature Climate Change, 4(5), pp.358-361. Available at: http://www.nature.com/nclimate/journal/v4/n5/full/nclimate2159.html?WT.ec_id=NCLIMATE201405. 
Cerri, L., 2010. POD considerations concerning the 60-day signal between Jason and Topex MSL. In OSTST 2010, Lisbon. Available at: http://www.aviso.altimetry.fr/en/user-corner/science-teams/sciteams/ostst-2010/ostst-2010-presentations.html.

Cerri, L. et al., 2010. Precision Orbit Determination Standards for the Jason Series of Altimeter Missions. , (August 2010). Available at: http://discovery.ucl.ac.uk/1334753/.

Couhert, A. et al., 2015. Towards the $1 \mathrm{~mm} / \mathrm{y}$ stability of the radial orbit error at regional scales. Advances in Space Research, 55(1), pp.2-23. Available at: http://www.sciencedirect.com/science/article/pii/S0273117714004219 [Accessed June 30, 2015].

Desjonqueres, J.-D., 2010. JA1 \& JA2 altimeter calibration and monitoring. In OSTST 2010, Lisbon. Available at: http://www.aviso.altimetry.fr/en/user-corner/science-teams/sci-teams/ostst2010/ostst-2010-presentations.html.

Henry, O. et al., 2014. Effect of the processing methodology on satellite altimetry-based global mean sea level rise over the Jason-1 operating period. Journal of Geodesy, 88(4), pp.351-361. Available at: http://link.springer.com/10.1007/s00190-013-0687-3.

15 Imel, D.A., 1994. Evaluation of the TOPEX/POSEIDON dual-frequency ionosphere correction. Journal of Geophysical Research, 99(C12), pp.24895-24906.

Kubitschek, D.G. \& Born, G.H., 2000. Radiation pressure forces, the anomalous acceleration, and center of mass motion, JPL-1214025 technical report, Colorado Univ., Available at: http://ntrs.nasa.gov/search.jsp?R=20020018564.

Legeais, J.-F., Ablain, M. \& Thao, S., 2014. Evaluation of wet troposphere path delays from atmospheric reanalyses and radiometers and their impact on the altimeter sea level. Ocean Science Discussions, 11(3), pp.1613-1642. Available at: http://www.ocean-scidiscuss.net/11/1613/2014/osd-11-1613-2014.html.

Lemoine, F.G. et al., 2010. Towards development of a consistent orbit series for TOPEX, Jason-1, and Jason-2. Advances in Space Research, 46(12), pp.1513-1540. Available at: http://www.sciencedirect.com/science/article/pii/S0273117710003224 [Accessed March 25, 2016 ].

Lemoine, J.M. \& Capdeville, H., 2006. A corrective model for Jason-1 DORIS Doppler data in relation to the South Atlantic Anomaly. Journal of Geodesy, 80(8-11), pp.507-523.

Leuliette, E. et al., 2010. An investigation into the source of the 59-day variations in Jason sea level. In OSTST 2010, Lisbon. Available at: http://www.aviso.altimetry.fr/en/user-corner/science-teams/sciteams/ostst-2010/ostst-2010-presentations.html. 
Ocean Sci. Discuss., doi:10.5194/os-2016-19, 2016

Manuscript under review for journal Ocean Sci.

Published: 25 May 2016

(c) Author(s) 2016. CC-BY 3.0 License.

Leuliette, E. \& Willis, J., 2011. Balancing the Sea Level Budget. Oceanography, 24(2), pp.122-129.

Lyard, F. et al., 2006. Modelling the global ocean tides: modern insights from FES2004. Ocean Dynamics, 56(5), pp.394-415. Available at: http://dx.doi.org/10.1007/s10236-006-0086-x.

Minster, J.F. et al., 1999. Annual cycle in mean sea level from Topex-Poseidon and ERS-1: inference on the global hydrological cycle. Global and Planetary Change, 20(1), pp.57-66. Available at: http://www.sciencedirect.com/science/article/pii/S0921818198000587 [Accessed March 25, 2016].

Munekane, H., 2013. Sub-daily noise in horizontal GPS kinematic time series due to thermal tilt of GPS monuments. Journal of Geodesy, 87(4), pp.393-401. Available at: http://dx.doi.org/10.1007/s00190-013-0613-8.

10 Nerem, R.S., 1995. Measuring global mean sea level variations using TOPEX/POSEIDON altimeter data. Journal of Geophysical Research, 100(C12), p.25135.

Ollivier, A. et al., 2012. Envisat Ocean Altimeter Becoming Relevant for Mean Sea Level Trend Studies. Marine Geodesy, (January 2013), p.120910084524009.

Ponte, R.M. \& Ray, R.D., 2002. Atmospheric pressure corrections in geodesy and oceanography: A strategy for handling air tides. Geophysical Research Letters, 29(24), pp.4-6. Available at: http://dx.doi.org/10.1029/2002GL016340.

Ray, R.D., 1999. A global ocean tide model from TOPEX/POSEIDON altimetry:GOT99.2. NASA Tech.Memo.209478. Available at: http://ci.nii.ac.jp/naid/80011373253/en/ [Accessed June 30, 2015].

Ray, R.D., 2013. Precise comparisons of bottom-pressure and altimetric ocean tides. Journal of Geophysical Research: Oceans, 118(9), pp.4570-4584. Available at: http://doi.wiley.com/10.1002/jgrc.20336 [Accessed June 30, 2015].

Rudenko, S. et al., 2012. New improved orbit solutions for the ERS-1 and ERS-2 satellites. Advances in Space Research, 49(8), pp.1229-1244. Available at: http://www.sciencedirect.com/science/article/pii/S0273117712000786 [Accessed June 30, 2015].

Saunier, J., Auriol, A. \& Tourain, C., 2016. Initiating an error budget of the DORIS ground antenna position: Genesis of the Starec antenna type C. Advances in Space Research. Available at: http://www.sciencedirect.com/science/article/pii/S0273117716001125 [Accessed March 25, 2016].

Schindelegger, M. \& Ray, R.D., 2014. Surface Pressure Tide Climatologies Deduced from a QualityControlled Network of Barometric Observations. Monthly Weather Review, 142(12), pp.48724889. Available at: http://dx.doi.org/10.1175/MWR-D-14-00217.1. 
Stammer, D. et al., 2014. Accuracy assessment of global barotropic ocean tide models. Reviews of Geophysics, 52(3), pp.243-282.

Zawadzki, L. \& Ablain, M., 2016. Accuracy of the mean sea level continuous record with future altimetric missions: Jason-3 vs. Sentinel-3a. Ocean Science, 12(1), pp.9-18. Available at: http://www.ocean-sci.net/12/9/2016/ [Accessed March 25, 2016].

Zelensky, N.P. et al., 2010. The puzzling 59-day altimeter data signal and possible causes. In OSTST 2010, Lisbon. Available at: http://www.aviso.altimetry.fr/en/user-corner/science-teams/sciteams/ostst-2010/ostst-2010-presentations.html.

Ziebart, M. et al., 2005. Combined radiation pressure and thermal modelling of complex satellites: Algorithms and on-orbit tests. Advances in Space Research, 36(3), pp.424-430. Available at: http://www.sciencedirect.com/science/article/pii/S0273117705000694 [Accessed March 25, 2016].

Zlotnicki, V., 1994. Correlated environmental corrections in TOPEX/POSEIDON, with a note on ionospheric accuracy. Journal of Geophysical Research, 99(C12), pp.24907-24914. 